through the wound. Some of the sutures were removed; pulse 104; bowels not open since the operation. To take half an ounce of castor oil immediately.

8th.-Sleeps well, and takes his nourishment freely; wound healing fast; large discharge of a mixture of pus and saliva of a very offensive character. Has no pain; pulse 96, rather weak. Bowels open two or three times since the castor oil.

9th.--In attempting to drink, a large portion passes out through the wound; which is, however, looking healthy. $\mathrm{He}$ complains of the unpleasant taste in his mouth from the discharge, in consequence of which a portion of the wound is left tree, for the escape of the discharge externally. Repeat the oil. A lotion of chlorinated soda applied to the part.

12th-Several of the ligatures came away; the wound is in a great measure healed; those parts at present un-united discharge freely. He takes his nourishment well, but feels very weak; passes quiet nights, and dozes a good deal during the day.

In consequence of his complaining of considerable weakness, with profuse perspiration, he was ordered compound infusion of roses an ounce and a half; sulphate of quinine, a grain; twice daily.

$22 \mathrm{nd}$. - Has been going on well since the last report: is gaining strength gradually; pulse stronger; wound healed, except at the upper part, from which there is a small discharge of matter and saliva. His mouth begins to appear rather drawn to one side (the left), more especially as all the dressings and bandages are left off. He is now able to articulate and open his mouth to some extent, and to employ some force in bringing the remains of the lower jaw in apposition with the upper.

29th.-Wound healed externally; internally, at the upper part, there is a small sinus, into which several salivary ducts open; there is also some purulent discharge, and these together, keep up an irritation which produces a continual spitting. He still complains of pain about the temporal muscle, which has troubled him more or less since the operation. His general health, however, is improving. He is gaining flesh his complexion is clear and healthy; and he now takes a good deal of exercise out of doors.

June 6th.-Is going on well; general health improving; to go out in a week.

\section{ACCOUNT OF A CASE OF AMYELITIC FCETUS.}

\section{Bx D. HOADLEY GABB, EsQ., M.R.C.S.E., Hastings, WITH REMARKS BY \\ W. TYLER SMITH, M.B. LOND.}

Tux following interesting, and I believe unique, case has a very evident bearing on the views advanced in my observations on the nature of the abdominal movements of pregnancy, (vide The LANCET, vol. i. 1848, p. 277.) I there brought forward a series of facts to show that the major part of these movements were uterine, and not fotal; and I quoted a remarkable case of M. Lallemand's, in which these supposed movements of the fotus co-existed with deficiency, both of the brain and spinal marrow. The following case resembles it in the com plete absence of the spinal marrow, but it is more carefully detailed. The abdominal movements were present, as in $\mathbf{M}$. Lallemand's case. I consider these cases alone would afford sufficient proof that the movements in question do not and cannot belong solely to the foetus. Where, in such a case, could the source of motion reside in the foetus, and how could it be excited in the absence of all connexion between the muscles and the nervous centres? Time was when the absurd notions that the uterus sat upright in utero during gestation, and that, at the time of labour, it assisted by its own efforts in it emergence from the womb, were as universal as the present belief that the abdominal movements of gestation are movements of the foetus. I am convinced that more correct observation will prove the latter to be as untenable as the former, of which, indeed, it seems to be a relic. I now quote from Mr. Gabb's excellent description.

"It will afford me much pleasure to give you a history of the case your letter referred to, which was not only interesting to me, from the malformation of the foetus, but also from the mother (who has previously had four healthy children) having attained a most enormous size, so that the abdominal parietes appeared on the verge of sloughing from distension; this was subsequently accounted for by the inmense quantity of liquor amnii.

"Another feature of the case was new to me, and occasioned me some anxiety. The uterus remained as enlarged for some days as that of a woman six months advanced in pregnancy and for a night and day after delivery as much liquor amni was discharged, though without pain, as is usual at an ordinary labour.

"The placenta came away easily; there was no hæmorrhage. The foetus, which was within a fortnight of its proper time, according to the mother's calculation, was small; it presented these peculiarities:-

"The head was placed without the intervention of a neck between the shoulders, so that the chin rested on the sternum. The face was natural, excepting being broader than usual.

"The skull consisted only of the frontal, the inferior portions of the temporal bones, (there were no squamous portions, and the anterior half of the occipital bone, so that there was no foramen.

"The brain was large enough to fill the skull if it had been perfect; it was merely covered behind, apparently by its membranes. The hemispheres were as plainly divided by the falx cerebri as they usually are on the removal of the calvarium.

"My impression is, that there was no cerebellum, but of that I am not quite certain.

"The posterior portions of the cervical and dorsal vertebræ were wanting; they appeared as if the integuments, together with all the vertebræ, excepting the bodies and transverse processes, had been removed with a knife, and had recently cicatrized.

"The ligamentum nuchæe was divided into two fasciculi, and attached to the transverse processes.

"There was no spinal cord-nor any rudiment of one-the bodies of the vertebrce were only covered by a thin, semi-transparent membrane.

"The other portions of the body were normal.

"The apparent motions of the foetus were so evident a day or two before its birth, that the mother drew her husband's attention to her dress being raised by them.

"These are all the peculiarities that a superficial examina. tion afforded. Circumstances would not permit me to dissect the foetus, which I much regret.

"P.S. - From the little resistance offered by the formation of the head of the child, I was not there until half an hour after its birth, as my house is a mile from where the mother resides. The child, the nurse informed me, was born dead, and, indeed, from the fact of the blood being coagulated in the funis, must have been so some time prior to its birth, as labour was very rapid."

There are many cases of amyelitic and anencephalic births on record, and some in which the brain and spinal marrow have both been absent, but I am not a ware of any other case in which, as in the present, the brain was tolerably well developed, with entire deficiency of the spinal marrow. Extra. uterine life is of course impossible in perfect amyelitic cases, from the absence of the medulla oblongata.

I ouglit not to omit this opportunity of thanking Mr. Gabb and several other gentlemen who have kindly sent me cases in illustration of the views $I$ have recently advanced.

W. T.S.

\section{AN ESSAY ON MEDICAL REFORM;}

WITH SUGGESTIONS FOR THE RE-ORGANIZATION OF THE MEDICAL PROFESSION.

By THOS. MICHAEL GREENHOW, EsQ., F.R.C.S., \&c., Newcastle-on-Tyne,

SURGEON TO THE NEWCASTLE INFIRMARY AND EYE INPIRMART.

"Sed longe alia est ars medica, et longe aliis difficultatibus implicita."

Tre following essay, in the words of its author, "furnishes a somewhat curious passage in the history of medical reform, it having been written many years ago, in competition for certain prizes offered by a body calling itself 'The Medical Reform Association,' to be placed in the hands of Mr. HoMk, M.P., and distributed by him."

In conformity with a promise long ago made to our correspondent, Mr. WAKLEY inquired of Mr. HUME-Whether he ever received the $£ 100$ which was to have been divided amongst the authors of the three best essays? from whom he receivesd it? to whom he paid it? and whether the hon. M.P. was ever consulted as to the merits of the different essays sent for competition? In reply to Mr. W stated that he had had the sum in question in his charge for a considerable length of time, but that he subsequently returued 
it, on application, into the hands of the party by whom it had rormerly been entrusted to him. The prizes, consequently, were never awarded - for reasons which were made known to (one at least of) the competitors by Dr. Epps.

"Whether this essay merited any of the prizes in question (says Mr. Greenhow) it is not for me to judge. How much literary justice and good faith there was in the assumption that none of the essays sent in were of sufficient merit, I shall not pretend to determine. I cannot help thinking, nevertheless, that the character of the proceeding is without precedent, as it will be without imitation, standing alone in its glory."

From the earliest periods of recorded history, the human constitution has been liable to organic or functional derangements, from various causes, accidental, moral, atmospherical, miasmatical, or from the abuse of those powers of enjoyment which are given us for the preservation of life, or the continuation of the species. Long before the art of treating, according to any scientific principles, the various aberrations from healthy action, or the numerous lesions of the members or organs of man, had assumed the dignity of a profession, empiricism and superstition pretended to cure or to relieve "the thousand ills that flesh is heir to." It is not necessary to trace the progress of knowledge from the rude application of supposed specifics, and the unfounded pretensions of designing imposture, to its gradual development into something like rational principles, founded, in the first place, on experience of the nature of disease, and the effects of remedies; and ultimately, on a knowledge of the structure, functions, and pathological conditions of the more important organs on whose actions life and health are dependent. It is enough to acknowledge the important truth that if the physical nature of man is exposed to innumerable causes of disease, the tendency of which is either to weaken its functions, to render useless some of its members, to produce lengthened suffering, or to shorten life, we are at the same time provided with many efficient resources, by the judicious employment of which, these effects may frequently be either entirely counteracted, or in some coisiderable degree mitigated. But, as might be easily anticipated, the nature and variety of these remedial agents are such as to require, for their successful application, knowledge varied, profound, and precise; perceptions quick, clear, and discriminating; and that promptitude, energy, and decision, which can only be attained by a mind of adequate natural endowments, imbued with a zealous love of science, in the pursuit of which it has engaged with ardour and diligence, under the direction of judicious and skilful teachers. Nevertheless, though this is a truth to which, perhaps, few would hesitate to give a ready assent, it must be acknowledged that, even in the present advanced state of general mental cultivation, there are those-and amongst the most highly-cducated of the community - who sometimes forget its application, and are credulous enough to yield to the pretensions of ignorant empiricism. They accord an occasional assent to the absurd proposition that the power of relieving organic disease is an intuitive gift, and that some minds, without pursuing the ordinary means of acquiring knowledge, are enabled to discern the occult disorder which threatens to terminate life, and to avert the event by the application of means, not unfrequently of powerful agency, to the use of which they have neither been directed by reason nor by experience, but by an unprincipled desire for gain, even at the hazard of sacrificing the lives of their deluded victims.

On the value and importance of a successful cultivation of the art of relieving and curing disease, in reference to the welfare and happiness of the community, it is unnecessary to enlarge; it will readily be acknowledged by every individual, and has been recognised by most governments in the provisions which they have adopted for its encouragement and protection. In our own country it has given rise to many institutions, into the practical effects of which, over the progress and actual state of medical science, it will naturally become our business to inquire. If they have failed in promoting it to the extent which must be desired by those engaged in its pursuit, it has probably arisen from the partial and imperfect objects which any of them have been intended to embrace; from their scope being limited to detached portions, instead of comprehending as parts of one great whole, which must be weakened and rendered inefficient by separation and dismemberment, the entire range of remedial science.

Of the utility of these institutions within certain limits we can scarcely entertain a doubt; but having attained their end to the degree supposed, their further influence over the progress of science may well admit of dispute. An advanced state of society demands institutions of a character more comprehensive and liberal than was either required or admissible in its earlier stages; and so it is with establishments intended to cherish the first dawnings of professional knowledge. In its infancy it might require restrictions and protection, which in its mature age are found injurious and cumbersome; their fashion necessarily passes away; they are behind the times in which we live, and ought to give way to institutions better calculated to contribute to the purposes of science, and the public good.

The consideration of the present state of medical science necessarily divides itself into two parts. The first relates to the actual progress of the various branches of knowledge which are to be considered as integral parts of medical science; the second, to the degree in which they are cultivated by the several classes of members into which the medical profession has been divided.

The sphere of professional knowledge has been con. tinnally widening and extending within the last half centuryanatomy and physiology, the basis of all useful, practical knowledge in medicine, have rapidly advanced through the labours of many eminent surgeons both at home and on the continent. Chemistry, within the same period, has by its extraordinary progress disclosed to us the nature and properties of many very important agents in the treatment of disease, while it has made known to us facts which materially assist us in their application, and enable us to draw correct conclusions as to their expected effects. The human system may be considered as a curious chemical laboratory acting under the influence of the superadded principle upon which life depends. By that principle the agency of remedies is nodoubt modified in a most essential manner; but still sufficient analogy may often be traced in their effects on the constitution to the established laws of chemical action to render a thorough knowledge of that science very valuable to the medical practitioner. The list of the materia medica has also been greatly enlarged of late years by the addition of numerous active medicines from the vegetable kingdom, which have been supposed to possess considerable influence in the relief of disease-and botany has been cultivated with success as a branch of medical science.

But perhaps the most important feature of modern medicine is the great advancement which has taken place in pathological anatomy. It is the power of connecting the symptoms of disease with the alterations in the condition of organic structure that must lead the physician to the most rational and successful principles of practice, and this connexion has of late years been traced with a degree of zeal and ability that has led to many valuable improvements in practice.

Medical jurisprudence, as it has been denominated, or the rules to be observed in giving or collecting such evidence, in criminal cases, as is dependent on medical science, is a branch of study in a great degree of recent origin, which has made rapid advances within a short period of time, and the neces sity of which is becoming daily more obvions, as a part of medical education.

In consequence of the progress which has thus been made in all the fundamental branches of professional knowledge, practical results of great value have been obtained in both medicine and surgery. In the former, much light has been thrown upon many of the most formidable diseases, their nature elucidated, their pathological history accurately defined, and their treatment rendered, in many instances, simple and efficient. Nor have the improvements in surgery been less important: not only have more correct views been introduced respecting many surgical diseases, but in the greater operations simplicity has often taken place of complexity, both in the instruments employed and in the mode of performing them; and in ophthalmic surgery the most remarkable progress is observable.

It would be easy to enlarge upon the several subjects which have been thus cursorily noticed, but it must necessarily involve details which appear somewhat irrelevant to the main object of this essay, and which, once entered upon, might be difficult to curtail within limits short of a complete historical sketch of every department of medical science. It is sufficient, therefore, to notice the greatly increased extent and precision of knowledge which modern cultivators of professional science have introduced into the study of medicine and surgery, and the practical benefits which have resulted. It is scarcely too much to affirm, that assuredly we discover in them one cause of the great increase in the average duration of human life which a few years have brought about.

But it wonld be of little moment to the welfare of society that such advances have been made in medical science, unless the several members of the profession have made 
similar advances in their attainments. We believe that to. a certain extent this is really the case, though we are firmly convinced, that under a wiser system of professional legislation these advances would have been very much more extensive. It is certain, however, that, taking the profession generally, its members constitute a more intelligent and seientific body than formerly. There always have been, and always will be, men who stand pre-eminent for natural talent, zeal in the pursuit of knowledge, and success in its acquisitionmen who stride over the entire field of professional science, and are continually enlarging its boundary. Such men cannot be taken for a-general standard-the many of the present age must be compared with the many of former ages, and it. cannot be denied, we believe, that they will gain. by the comparison. Not only have anatomy and operative surgery been. very generally cultivated with considerable success by a. majority of practitioners, but their knowledge of the general principles of treating disease has become more accurate, and their practice proportionally successful. Their prescriptions, for the most part, evince correct discrimination of the symp. toms of disease, a clear perception of the true indications to be held in view in treatment, and an efficient application of remedies. We do not mean to affirm that in all these respects are any members of the profession perfect, much less the general mass of practitioners, but simply that a decided advance in the degree of knowledge and practical skill is generally observable. The same remarks apply to the condition of surgery throughout the country. It is well known, that some years ago few surgeons in the country, except those attached to county hospitals, considered themselves qualified to undertake the performance of operations, espe. cially the greater ones, in surgery; whereas, in every town, if not in almost every village, may now be found surgeons of sufficient knowledge and enterprise to perform, successfully, the most important; and though example and emulation may sometimes have excited a few to overrate their own attainments and operative skill, we cannot but conclude that this confidence in themselves is generally dependent on a substantial advancement in knowledge.

Whatever imperfections may be hereafter pointed out in the existing institutions, it would be unfair not to admit that they (at any rate, the College of Surgeons, and Society of Apothecaries) have been eminently useful in promoting this increased degree of acquirement in the great mass of the profession. But in awarding to them their due praise, let us not attribute to them too much. It cannot be doubted, that the progress of general intelligence in the community at large has necessarily carried along with it those engaged in medical as well as other pursuits, and that the public would not be content to concede their confidence to persons who stood still in their particular vocation, while all the rest of the world were advancing. Nor must we forget the powerful and permanent impulse given to surgical science during the late protracted war, which called forth the energies of so many men of eminent talents, (some of whom still flourish in many of the countries of Europe, and afforded a field for practical surgery unknown in the previous history of the profession.

From these and other causes, the state of medical science, both in the number and the extent of its constituent departments, and in the degree of its general diffusion, must be considered as exhibiting a gratifying subject of contemplation; but the satisfaction thus excited must be greatly lessened by the imperfect state of its organization, in consequence of the impolitic and inefficient constitution of the legalized institutions which are placed at its head.

The effect of these institutions has been, to render the profession a heterogeneous mass of practitioners of various grades and qualifications, without order, without definite privileges, and with pretensions and interests continually placed in opposition to each other. They hold out to their members and licentiates the hope of protection from unqualified competitors, which is in the highest degree fallacious; and while we should seem to possess a greater number of bulwarks against quackery and imposture than any other country in the world, there is none where they are so openly and successfully prac tised. For besides the several classes of physicians sanctioned by the Royal College, the graduates of the English and Scottish universities, the members of the College of Surgeons, and the licentiates of the Society of Apothecaries, there are innumerable prescribing chemists, notorious empirics, boneetters, and vendors of all deseriptions of nostrums and specifics. Our newspapers abound with advertisements of cures effected by patent medicines, the sale of which is expressly authorized by permission of government, and there seems to bo neither obstacle nor limit to the fraudulent and pernicious pretensions of any who may be unprineipled and courageous enough to prey upon public credulity.

This is a state of things which few will attempt to defend, and which, if the medical profession be a fit subject of legislation at all, ought surely to be altogether superseded by a more harmonious arrangement, by collecting together the genuine but disjoined parts, and rooting out the anomalous excres. cences, which tend alike to disfigure the order and beauty of the whole, and to curtail the extent of its usefulness.

(To be continued.)

\section{Analp\&es}

\section{COMMUNICATIONS IN MS. RECEIVED FOR PUBLICATION IN THE LANCET.}

"L'auteur se tue à allonger ce que le lecteur se tue à abréger."

\section{Air-Baths for the Treatment of Cholera.}

AMONGST other communications the following have reached us relative to the construction of these appliances:-

"A circular tin-case or - box, about six irches in diameter, and the same in depth, forms a receptacle for a spirit lamp. It is perforated around the bottom with small openings forthe admission of air, and furnished at the side with a small door for the insertion of the lamp. At the top it is dome-shaped or conical, and terminates in a funnel or chimney about three inches in diameter, which, at the height of about two feet, gives off, at an obtuse angle, an arm, the extremity of which is passed under the bed-clothes at the foot of the bed. A cradle is placed over the patient to support the bed-clothes, and allow a space for the collection of the heated air, which is thus brought in contact with every part of the body, and the bed-clothes are tucked closely in at the sides, and under the chin, to prevent its escape. To set the apparatus in action, nothing more is necessary than to place it, and light the lamp. Spirits of wine may be burnt, either with a very large cotton or an Argand burner. The tin case may be riveted to an iron plate, to give it increased steadiness, and the funnel, instead of being in one piece, may be made of two, one sliding into the other, so as to adapt it to the height of the bed.

In diseases attended with internal congestion, it quickly produces a powerful reaction toward the surface. I have often used it, and with great success. The advantages of this apparatus are,- that its action is immediate; it can be used with out moving the patient at all, and consequently exposes him to no fatigue; it is also very compact and convenient. I do not know any exclusive maker of it; but there can be no difficulty in manufacturing a thing so simple, and the expense is but trifling:-I am, Sir, your obedient servant,

"Chepstow Villa, Notting-hill, 1848."

"Ed. HART Vinen, M.R.C.S.

\section{ANoth ER correspondent states-}

"I did not know where such an article could be procured and having occasion for its use, I lately designed one which I find answers very well, and can be made very readily, and at very little expense. I obtained a planed deal board, two feet long, one foot wide, one inch thick; this I had cut into a semicircle, and perforated in the centre by a hole, one inch in diameter, to receive a curved tin tube, two feet long; this formed the base or end; to the curve of this board I had stout wicker rods, three feet six inches long, at intervals of two inches, made secure by being inserted into the wood, and worked across, at one foot distance, with wicker or basket work, and at their ends to form a semicircle the same size: as the board. The tin tube is circular, curved in the shape of a horn; the small end one inch in diameter, and made to fit airtight in the hole of the board; the large end three inches in diameter. A small spirit lamp completes the apparatus.

"Every surgeon I presume to be familiar with the way in which it is applied. I would add, that $I$ find it more efficient if temporarily covered with any kind of Macintosh'd material. -I am, Sir, yours \&c., FrancIS W ARD, M.R.C.S.E. \&c.

"Balham-hill, Surrey, September, 1848."

A THIRD correspondent recommends an arrangement very similar to the foregoing.

"It consists of a slight frame, similar to a fracture cradle, about six feet in length, two feet and a half broad, and one foot high. This frame, for the convenience of carriage, is 